\title{
The link: trauma and substance abuse
}

\begin{abstract}
Trauma "is categorized as an overwhelming life-changing experience (and) is typically a physical and/or emotional shock to the very fiber of one's being."It is a priority that those who experience trauma in their lives seek help from a licensed professional to deal with the emotional damage caused by the trauma(s) and to be taught necessary coping skills to prevent them from seeking solace in unhealthy ways like abusing drugs and/or alcohol. Research proposes that all types of trauma and the aftermath that follows will likely impact the "exposed population's behavioral health, resulting in an increase in mental and substance use disorders, along with a decline in perceived quality of life". ${ }^{1}$ Survey results teach us that more than $70 \%$ adolescents receiving treatment for substance abuse across the country have a history of trauma in their lives.
\end{abstract}

Volume 5 Issue 4 - 2016

\section{Leslie Dawn Culpepper \\ Argosy University, USA}

Correspondence: Leslie Dawn Culpepper, Argosy University, USA, Tel 8064489420,Email idawnculpepper@yahoo.com

Received: November 0I, 2016 | Published: March 19, 2016

\section{Introduction}

Research question: What is the correlation between specific types of trauma and subsequent substance abusing behaviors? This topic is important as a psychology issue because addiction is a negative health behavior ${ }^{2}$ and it is a growing problem in the United States. Not only that but it is a priority that those who experience trauma in their lives seek help from a licensed professional to deal with the emotional damage caused by the trauma(s) and to be taught necessary coping skills to prevent them from seeking solace in unhealthy ways like abusing drugs and/or alcohol. There are many strategies in addressing substance abuse disorders and the following literature review will examine prior research that helps support the hypothesis. There will also be information about non-treatment results and the dangers of thought suppression that often leads to abusing drugs and alcohol as a means of easing the emotional pain. Research proposes that all types of trauma and the aftermath that follows will likely impact the "exposed population's behavioral health, resulting in an increase in mental and substance use disorders, along with a decline in perceived quality of life".

\section{Literature review}

The world today is chock-full of extreme life events "including war, ethnic cleansing, genocide, terrorist attacks, as well as tsunami, earthquakes, floods, tornadoes, and hurricanes-so-called 'natural disasters' whose impact is frequently shaped by past and present human actions and inactions". ${ }^{3}$ There are even more types of psychological trauma that we as individuals experience in our lifetime. It is difficult to pinpoint which types are more severe because each person handles these events differently. Nevertheless, traumatic life experiences that are left unresolved have a way of producing negative outcomes that very often end in unrelenting dependence on drugs and/or alcohol as a way of easing the emotional pain caused by the original trauma. According to Carole Bennett, trauma "is categorized as an overwhelming life-changing experience (and) is typically a physical and/or emotional shock to the very fiber of one's being." This supports the idea that because trauma takes such a toll on our psyche, it is imperative that we do our part to seek help in the healing process to avoid further consequences that arise from selfmedicating. Each person has his/her own demons, and more often than not, symptoms of specific trauma affects us in similar ways. For example, the symptoms brought on by the loss of a parent or primary caregiver include higher than normal levels of anxiety and depression which heightens sensitivity to everyday stressors. Post- traumatic stress disorder (PTSD) symptoms include psychologically reliving the traumatic event (abuse, combat, assault, natural disasters) which increases physiological arousal as well as overall emotional numbing (as a defense mechanism). All of which cause flashbacks, nightmares, concentration difficulties, inability to sleep, irritability, and the inability to develop close relationships with others, just to name a few. ${ }^{4}$ Those who have been physically and/or sexually abused often have problems with anxiety (panic attacks), low self-esteem, and personality disorders. Particularly, the relationship between traumatic experiences and subsequent substance use/abuse is well-established. The National Survey of Adolescents states that "teens who have had experienced physical or sexual abuse/assault were three times more likely to report past or current substance abuse than those without a history of trauma". ${ }^{5}$ Furthermore, survey results each us that more than $70 \%$ adolescents receiving treatment for substance abuse had a history of trauma. ${ }^{6,7}$ Trauma is part of an almost universal experience because it has no boundaries with regard to race, gender, geography, socioeconomic status, age, or sexual orientation. Please recognize that unaddressed trauma significantly increases the risk of mental and substance use disorders, chronic physical diseases, and early death.

\section{Methods}

\section{Procedure/Instruments/Participants}

Correlational research design was chosen to measure the relationship between trauma and substance abuse. The sample for this study includes peer reviewed articles that address samples of populations of people who have experienced significant trauma and those who abuse substances. The sample generalizes to the population because by observing a limited number of patients' cases whose histories include specific traumatic life experiences that result in various substance-abusing behaviors, one can extend the conclusions to cover all of the unobserved cases from the same category. Inclusion criteria will include all types of trauma that are a direct catalyst to addictive behavior. Those who have never experienced any life changing traumatic events will be excluded. The hypothesis is that trauma does very often precede substance abusing behavior and will be proven by using the data from previous researchers along with the responses from interviewees at an Alcoholics Anonymous meeting. The participants will be asked to share whether a specific traumatic event took place in their lives, and if so what was it, and which substance did they turn to? Furthermore, they will be asked if they believe the named traumatic experience led to, or could be related to their substance abusing behavior. 
The archival research shows how the studies prove reliability for the hypothesis. The studies cover a range of different types of traumas and the affect the traumas had on individuals from all walks of life in terms of self-medication/substance-abuse. For the interview sample, 30 people will be chosen from the sign-in sheet at an Alcoholics Anonymous meeting using simple random sampling. Anyone who frequents AA meetings feels strongly that the data gathered from these interviews will have high content validity because AA is a place where folks go to find solace; a place to open up to others who have been in the same shoes; a place where nobody is judged for the bad choices they have made; a place to be honest with themselves.

\section{Ethical issues}

Regarding the interviews with the AA participants, some questions could caused stress for some but this cannot be avoided. An AA meeting full of addicts and recovering addicts is one of the best places for this to happen. It is the researcher's obligation to be aware of all of the participant's behavior and distress levels during the interview. Should anyone show signs of a problem, there are program sponsors within an arm's length to help. However, great respect will be shown to them and the answers to the questions because "the scientific behaviors that are associated with respect are having a valid research design, having a competent researcher, the identification of the consequences, appropriate selection of subjects, voluntary informed consent, and compensation for injury" ${ }^{8}$ It is a priority to treat the participants with respect with a sense of gratitude and appreciation for their cooperation as we enable gather our data. Furthermore, it is through these people, the self-proclaimed addicts that make up AA, that we get the truth about the darkness of substance abuse and the miserable loneliness that seems to follow addicts around like a monkey on their back. Clearly, it would be unethical to ignore the plethora of knowledge that they have to offer the field of research. ${ }^{9-12}$

\section{Results}

Over and over again, studies show a correlation between a history of physical and sexual abuse with substance abuse, with alcohol and various drugs "often serving as self-medication for the experiential impact of trauma". This leads to the revolving door of substance abusing women getting into prostitution or exchanging sex for drugs which makes them more vulnerable to further traumatic experiences like rape or other violence.

\section{Discussion}

Data suggests "that exposure to trauma in the form of a natural disaster may, indeed, lead to increases in excessive drinking, at least in terms of social indices of abusive drinking". Another study of 1,018 teenagers, Newcomb found that life events experienced over the past 6 months were significantly correlated with the use of the following substances: alcohol, marijuana, cocaine, and psychedelics. The data from the 30 sample participants from Alcoholics Anonymous was as expected. Of the 15 men interviewed, 10 of them reported a traumatic life event before the age of 13 , with 8 of those being suppressed. The data revealed that all 15 women interviewed had suffered a traumatic life experience. Of the 15 women in the sample, 13 of them had faced traumatic events before the age of 11 with 7 of those being suppressed events. All of the participants felt strongly that these experiences played a major role in their addiction.

Considering any threats to internal validity, the data shows sufficient evidence to substantiate the claim and the external validity speaks for itself because AA meetings are a perfect place to generalize about a population of substance abusers.
The implications of the findings remind us that it is important to note that my empirical research showed that individuals who suffered from trauma were less likely to have lifetime substance use but more likely to have used/abused substances in the past year. This implies that when an individual experiences a traumatic event, they usually seek to ease their emotional pain through self-medicating but statistics prove substance abuse to not be a "lifelong fix" for most. In addition, "we also found that individuals with histories of childhood abuse and neglect reported a significantly higher number of different drugs used in the past year" (Widom, 398). From the research examined we can safely speculate that most of these abused and neglected individuals turned to drugs and/or alcohol because they lacked constructive coping skills.

\section{Acknowledgments}

None.

\section{Conflicts of interest}

Author declares there are no conflicts of interest.

\section{Funding}

None.

\section{References}

1. Huang Larke. Strategic Initiative \#2: Trauma and Justice. Office of Behavioral Health Equity.

2. Taylor SE. Health Psychology. (7th edn), McGraw-Hill, New York, USA. 2009.

3. Kammerer Nina, Mazelis Ruta. After the Crisis Initiative: Healing From Trauma After Disasters. 2006.

4. Stewart SH. Alcohol abuse in individuals exposed to trauma: A critical review. Psychol Bull. 1996;120(1):83-112

5. http://search.proquest.com.libproxy.edmc.edu/docview/614327854/ abstract/138628EAFC5D2DAB80/4?accountid=34899

6. Kilpatrick DG, Saunders BE, Smith DW. Youth Victimization: Prevalence and Implications [Electronic]. U.S. Department of Justice, Office of Justice Program, National Institute of Justice. 2003.

7. Funk RR, Mc Dermeit M, Godley SH, et al. Maltreatment issues by level of adolescent substance abuse treatment: the extent of the problem at intake and relationship to early outcomes. Child Maltreat. 2003;8(1):36-45.

8. Deykin EY, Buka SL. Prevalence and Risk Factors for Posttraumatic Stress Disorder Among Chemically Dependent Adolescents. Am J Psychiatry. 1997;154(6):752-757.

9. Ogbeide, Stacy A. Ethical Issues in Survey Research. The School of Professional Psychology at Forest Institute Eye on Psi Chi. 2009.

10. Bennett Carole. How Trauma Can Lead to Addiction. Addictive Intervention.

11. Newcomb MD, Harlow LL. Life events and substance use among adolescents: Mediating effects of perceived loss of control and meaninglessness in life. J Pers Soc Psychol. 1986;51(3):564-577.

12. Widom CS, Marmorstein NR, White HR. Childhood victimization and illicit drug use in middle adulthood. Psychol Addict Behav. 2006;20(4):394-403.

13. Substance Abuse and Mental Health Services Administration \& National Association of State Mental Health Program Directors. The damaging consequences of violence and trauma. 2004. 